RESEARCH

\title{
MDR1 inhibition increases sensitivity to doxorubicin and etoposide in adrenocortical cancer
}

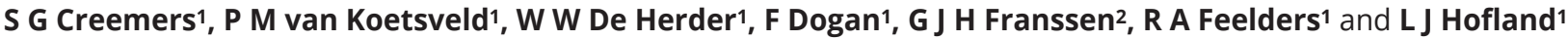

1Department of Internal Medicine, Division of Endocrinology, Erasmus MC, University Medical Center Rotterdam, Rotterdam, the Netherlands 2Department of Surgery, Erasmus MC, University Medical Center Rotterdam, Rotterdam, the Netherlands

Correspondence should be addressed to L J Hofland: I.hofland@erasmusmc.nl

\begin{abstract}
Chemotherapy for adrenocortical carcinoma (ACC) has limited efficacy and is accompanied by severe toxicity. This lack of effectiveness has been associated with high tumoral levels of the multidrug resistance (MDR) pump P-glycoprotein (P-gp), encoded by the MDR1 gene. In this study, effects of P-gp inhibition on the sensitivity of ACC cells to cytotoxic drugs were evaluated. MDR1 mRNA and P-gp expression were determined in human adrenal tissues and cell lines. H295R, HAC15 and SW13 cells were treated with mitotane, doxorubicin, etoposide, cisplatin and streptozotocin, with or without the P-gp inhibitors verapamil and tariquidar. Cell growth and surviving fraction of colonies were assessed. MDR1 mRNA and P-gp protein expression were lower in ACCs than in adrenocortical adenomas ( $P<0.0001 ; P<0.01$, respectively). MDR1 and $P$-gp expression were positively correlated in ACC $(P<0.0001, \rho=0.723)$. Mitotane, doxorubicin, cisplatin and etoposide dose dependently inhibited cell growth in H295R, HAC15 and SW13. Tariquidar, and in H295R also verapamil, increased the response of HAC15 and H295R to doxorubicin (6.3- and 7.5-fold $\mathrm{EC}_{50}$ decrease in $\mathrm{H} 295 \mathrm{R}$, respectively; all $P<0.0001$ ). Sensitivity to etoposide was increased in H295R and HAC15 by verapamil and tariquidar (all $P<0.0001$ ). Findings were confirmed when assessing colony formation. We show that cytotoxic drugs, except streptozotocin, used for ACC treatment, inhibit ACC cell growth and colony formation at clinically achievable concentrations. P-gp inhibition increases sensitivity to doxorubicin and etoposide, suggesting that MDR1 is involved in sensitivity to these drugs and could be a potential target for cytotoxic treatment improvement in ACC.
\end{abstract}

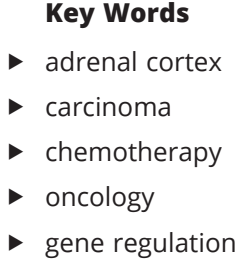

Endocrine-Related Cance (2019) 26, 367-378

\section{Introduction}

Adrenocortical carcinoma (ACC) is a highly malignant disease with limited treatment options (Creemers et al. 2016a). The only curative treatment is tumor-directed surgery (R0 resection) in case of local disease. The high recurrence rates (30-50\%) after surgery, especially in highrisk patients, provide the rationale for adjuvant treatment with mitotane as standard of care (Bellantone et al. 1997,
Hahner \& Fassnacht 2005, Allolio \& Fassnacht 2006, Fassnacht et al. 2009, Grubbs et al. 2010, Libe et al. 2015, Margonis et al. 2016). In case of progression of advanced disease, mitotane can be combined with cytotoxic drugs. In the first randomized, controlled trial in ACC, the FIRM-act trial, mitotane in combination with etoposide, doxorubicin and cisplatin (M-EDP) resulted in a longer 
median progression-free survival compared to patients receiving mitotane and streptozotocin (Fassnacht et al. 2012). However, the median overall survival for this regimen was still only 14.8 months, but is now considered the treatment of choice (Fassnacht et al. 2012). These data suggest that the resistance to chemotherapy is still a major impediment of successful systemic treatment of ACC patients. The limited efficacy of chemotherapy in ACC has been associated with the presence of high levels of P-glycoprotein (P-gp) in normal and tumoral adrenal tissue, an enzyme which actively pumps a variety of substrates like chemotherapy out of the cell (Flynn et al. 1992, Sharom 2008). P-gp is also expressed in several other types of cancer, such as colon, kidney, liver and pancreas tumors (Goldstein et al. 1989). Data on the role of mitotane as P-gp inhibitor are equivocal. Mitotane has been shown to inhibit P-gp - encoded by the multidrug resistance protein 1 (MDR1) gene - activity in vitro, suggesting that this could reverse the chemoresistant character of ACC (Bates et al. 1991, Gagliano et al. 2014). In contrast, Theile and colleagues demonstrated the induction of not only P-gp, but also MRP2 (MDR1-related protein 2) and breast cancer resistance protein (BCRP), under mitotane treatment in vitro (Theile et al. 2015). A phase II trial in 35 ACC patients investigating mitotane as a P-gp antagonist in combination with doxorubicin, etoposide and vincristine showed no in vivo $\mathrm{P}$-gp inhibition by mitotane (Abraham et al. 2002). The response rate to the chemotherapeutic drugs in combination with mitotane was $22 \%$, a percentage difficult to interpret due to the lack of comparison in this study with mitotane or chemotherapy monotherapy (Abraham et al. 2002).

Several P-gp inhibitors have been described in literature. Verapamil is a first-generation P-gp inhibitor and substrate (competitive inhibitor), first described in 1981 (Tsuruo et al. 1981, Sharom 2008). Although verapamil was able to enhance drug accumulation in vitro, its clinical application is somewhat limited due to the challenging balance between the required doses to inhibit P-gp and potential verapamil-associated toxicity (Benson et al. 1985, Raderer \& Scheithauer 1993). Tariquidar (XR9576), a non-transporter P-gp inhibitor, belongs to the third-generation P-gp inhibitors, described as most selective and potent inhibitors obtained by design (Palmeira et al. 2012). Tariquidar inhibits the basal ATPase activity associated with P-gp (Martin et al. 1999) and has shown to inhibit P-gp activity in ACC patients in vivo (Menefee et al. 2008). Tariquidar also inhibits BCRP, another frequently studied ATP-binding cassette (ABC) protein associated with decreased accumulation of anticancer drugs (Kannan et al. 2011). The specificity depends upon the concentration and the relative density and capacity of P-gp vs BCRP. To the best of our knowledge, the effect of tariquidar on the efficacy of cytotoxic drugs has not yet been tested in vitro for treatment of ACC.

The aim of the present study is to further explore the potential value of inhibiting P-gp activity. We therefore assessed MDR1 mRNA and P-gp expression in normal adrenals (NAs), adrenocortical adenomas (ACAs) and ACCs. Thereby, we evaluated the effects of the currently clinically used cytotoxic drugs, in combination with verapamil, and tariquidar, on the growth of human adrenocortical cancer cells.

\section{Materials and methods}

\section{Adrenocortical tissues}

Adrenocortical tissues were obtained between June 1994 and August 2016 at the Department of Surgery, Erasmus MC, Rotterdam. Directly after resection, adrenal tissues were embedded in Tissue-Tek and stored at $-80^{\circ} \mathrm{C}$. Diagnosis was confirmed using the Weiss score or Van Slooten index (van Slooten et al. 1985, Lau \& Weiss 2009), dependent on the year of diagnosis. Normal adrenals were collected during nephrectomy and confirmed by the pathologist as being normal. Patient and tumor characteristics were obtained from electronic patient records. The study was approved by the Medical Ethics Committee of the Erasmus University Medical Center, and informed consent was obtained from all patients.

\section{Real-time quantitative PCR}

MDR1 mRNA expression was measured in cell lines and adrenocortical tissues. RNA isolation, cDNA synthesis and RT-PCR were performed as previously described, but using other primers (Supplementary Table 1, see section on supplementary data given at the end of this article; Sigma-Aldrich) (Creemers et al. 2016b). Three housekeeping genes were used to normalize mRNA levels using the Vandesompele method: hypoxanthineguanine phosphoribosyl transferase 1 (HPRT1; SigmaAldrich), Beta-actin (B-actin; Thermo Fisher Scientific) and glucuronidase beta (GUSB; Thermo Fisher Scientific) (Vandesompele et al. 2002).
(C) 2019 Society for Endocrinology Published by Bioscientifica Ltd. Printed in Great Britain 


\section{P-gp immunohistochemistry}

Two tissue microarrays (TMA) comprising specimens from NAs, ACAs and ACCs were constructed, as previously described using the automated TMA constructor (ATA-27 Beecher Instruments, Sun Prairie, WI, USA) available at Erasmus MC, Department of Pathology (Papathomas et al. 2014). For an optimal representation, an expert pathologist identified three areas per specimen in hematoxylin and eosin-stained slides. Cores with a diameter of $1 \mathrm{~mm}$ were extracted from 'donor' blocks and brought into the 'recipient' paraffin block at predefined coordinates. In addition, formalin-fixed paraffinembedded whole sections were used from three cases not included in the TMA. Five micrometer sections were cut and used for immunohistochemistry (IHC). Sections were deparaffinized, rehydrated and heated for $20 \mathrm{~min}$ in TRIS-EDTA buffer (pH 9.0). Endogenous peroxidase was blocked for $15 \mathrm{~min}$ in hydrogen peroxide/PBS 3\% solution in darkness. Afterward, sections were washed and incubated with the rabbit monoclonal anti-P-gp antibody (dilution 1:500; ab170904; Abcam), overnight at $4^{\circ} \mathrm{C}$. After several wash steps, sections were incubated for 30 min with the second antibody horseradish peroxidase rabbit/mouse, where after bound antibody was visualized with freshly prepared DAB+ Chromogen $100 \mu \mathrm{L}$ (both Dako Detection System). Slides were counterstained with hematoxylin and coverslipped. Sections were scored blind for tissue type by two investigators ( $\mathrm{S} \mathrm{G} \mathrm{C,} \mathrm{L} \mathrm{J} \mathrm{H)}$ independently of each other using a semi-quantitative well-established immunoreactivity score (IRS), calculated by the product of the percentage positive cells $(4,>80 \%$; $3,>51-80 \% ; 2,>10 \% ; 1,0)$ and intensity of staining (3, strong; 2 , moderate; 1 , mild; 0, no staining) (Remmele $\&$ Stegner 1987).

\section{Cell lines and culture conditions}

Three available human ACC cell lines were used: H295R, HAC-15 and SW13 obtained from the American Type Culture Collection, ECACC (Salisbury, Wiltshire, UK) and from Dr W Rainey (as a kind gift), respectively. Short tandem repeat profiling using a Powerplex Kit (Promega) of NCI-H295R and SW13 gave results consistent with the ATCC database. HAC15 showed a genetic profile identical to H295R, which is consistent with a previous report by Rainey et al. (Wang \& Rainey 2012). Culture conditions were described in detail previously (van Koetsveld et al. 2006). Mitotane, etoposide and verapamil stock solutions were diluted in absolute ethanol (EtOH), whereas doxorubicin, cisplatin and streptozotocin were diluted in $\mathrm{H}_{2} \mathrm{O}$. Tariquidar was diluted in $100 \%$ DMSO. All compounds were obtained from Sigma-Aldrich, except tariquidar, which was obtained from Tocris Biosciences (Abingdon, United Kingdom). To assess the optimal concentration of verapamil and tariquidar for the combination experiments with cytotoxic drugs, a doseresponse curve was obtained for verapamil and tariquidar on cell growth in all three cell lines. After trypsinization, cells were plated at a concentration of 100,000, 75,000 and 20,000 cells per well for H295R, HAC15 and SW13, respectively, in order to obtain $80 \%$ confluency at the end of the experiment. The doubling times of H295R, HAC15 and SW13 are 30, 49 and $22 \mathrm{~h}$, respectively (data not shown). The next day, incubations were started in quadruplicate and control cells were vehicle treated. Medium and compounds were refreshed after 3 days. All cell culture experiments were carried out at least twice in quadruplicate.

\section{Cell proliferation assay}

Dose-dependent effects of mitotane, doxorubicin, cisplatin, etoposide and streptozotocin, with or without the P-gp inhibitors, were assessed on cell amount after 7 days of treatment. After 7 days of cell culture experiments, media were removed and plates were stored at $-20^{\circ} \mathrm{C}$ until DNA measurement. Measurement of total DNA was performed with the bisbenzimide fluorescent dye (Hoechst 33258, Sigma-Aldrich) as previously described (Hofland et al. 1990).

\section{Colony forming assay}

The colony forming assay (CFA) is considered the gold standard for measuring the effects of cytotoxic agents on cancer cells in vitro. We determined the effects of cytotoxic drugs with and without verapamil or tariquidar on colony formation in H295R, HAC15 and SW13. Effects on surviving fraction and colony size were assessed at cell linespecific concentrations of cytotoxic drugs that appeared to be effective in cell growth inhibition at monolayer culture $\left(\mathrm{EC}_{50}\right.$ values after 7 days). Concentrations were adjusted when too strong or no effects were observed on colony formation. Final concentrations were 5, 10 and $25 \mu \mathrm{M}$ for mitotane and $0.01,0.01$ and $0.05 \mu \mathrm{M}$ for doxorubicin in H295R, HAC15 and SW13, respectively. For etoposide, $0.1 \mu \mathrm{M}$ was used in all cell lines, whereas a concentration of $1 \mu \mathrm{M}$ was used for cisplatin. For verapamil and tariquidar, $10 \mu \mathrm{M}$ and $1 \mu \mathrm{M}$ were used, respectively. Plates were 
coated with $1 \mathrm{~mL}$ poly-L-lysine $(10 \mu \mathrm{g} / \mathrm{mL})$, where after 3000,1500 or 500 cells were plated in a six-well plates for H295R, HAC15 and SW13, respectively. After 1 day, drug treatment was initiated. Media were removed after 3 days and refreshed without treatment. After 2 weeks, the cells were washed and fixed. Cells were colored with hematoxylin, and amounts and sizes of colonies were measured using MultiImage TM Light Cabinet (Alpha Innotech). Surviving fraction was calculated as previously described (Franken et al. 2006).

\section{Statistical analysis}

For statistical analysis, Graphpad Prism 6.0 (Graphpad Software) and SPSS Statistics 21 (SPSS 21.0; SPSS Inc.) were used. Kruskal-Wallis, followed by Dunn's multiple comparisons test, or the Mann Whitney $U$ test when applicable was used to assess the differences in MDR1 mRNA and P-gp expression levels between different adrenal tissues. Correlations were tested using Spearman's rank coefficient. Non-linear regression curve fitting program was used to calculate the $\mathrm{EC}_{50}$ values on cell growth in the ACC cell lines. For analysis of the combined effect of P-gp inhibitors and cytotoxic drugs on cell growth and colony formation, verapamil or tariquidar monotherapy was set as control. One-way ANOVA with Tukey's multiple comparisons test was used to assess the differences in colony formation between monotherapy and combination of cytotoxic drugs with P-gp inhibitors.
Values of $P<0.05$ were considered significant. Data are presented as mean \pm s.E.M., unless specified otherwise.

\section{Results}

\section{Patient characteristics}

Ten NAs, obtained during nephrectomy, 16 ACAs and 42 ACCs were included. MDR1 mRNA expression was assessed in 58 adrenal specimens (8 NAs, 13 ACAs and 37 ACCs), while P-gp protein expression, as determined by IHC, was analyzed in 59 tissues (7 NAs, 14 ACAs and 38 ACCs). Four of the 42 ACC were recurrent cases, and two patients received mitotane before surgery. There were no patients, both primary and recurrent cases, who received chemotherapy before surgery. Patient and tumor characteristics are listed in Table 1.

\section{MDR1 MRNA and protein expression in human adrenocortical carcinoma cell lines and tissues}

MDR1 mRNA expression was higher in H295R cells compared to HAC15 $(P<0.05$; Fig. 1A). MDR1 mRNA expression could not be detected in SW13 cells. MDR1 mRNA expression was lower in ACCs compared to ACAs and NAs, with a 7.7-fold lower median expression level in ACC than in ACA $(P<0.0001 ; P<0.01$, respectively; Fig. $1 \mathrm{~B})$.

P-gp expression, as determined by IHC, was high in almost all adrenal tissues, with a mean IRS of

Table 1 Patient and tumor characteristics of patients included in this study.

\begin{tabular}{lcc}
\hline & Adrenocortical carcinomas $(n=42)$ & Adrenocortical adenomas $(n=16)$ \\
\cline { 1 - 2 } Mean age at diagnosis (years, median, IQR) & $52(42-65)$ & $45(38-56)$ \\
Mean follow-up (months, median, IQR) & $18.5(8.0-89)$ & $31(13-55)$ \\
Male (\%) & $20(48 \%)$ & $3(19 \%)$ \\
Mean tumor size (cm, median, IQR) & $14(8.0-19)$ & $2.70(1.6-4.8)$ \\
Secretion & & \\
Androgens & $9(21 \%)$ & $1(6 \%)$ \\
Glucocorticoids & $20(48 \%)$ & $6(38 \%)$ \\
Mineralocorticoids & $2(5 \%)$ & $5(31 \%)$ \\
Precursors & $5(12 \%)$ & $0(0 \%)$ \\
Estradiol & $4(10 \%)$ & $0(0 \%)$ \\
Non-secreting & $15(36 \%)$ & $4(25 \%)$ \\
Weiss score (median, IQR) & $6.0(5.0-7.0), n=35$ & $0.00(0.0-0.8)$ \\
VanSlooten index (median, IQR) & $21(18-25), n=36$ & $1.6(1.6-1.6)$ \\
ENSAT & & $1.6)$ \\
I & $2(5 \%)$ & $2(88 \%)$ \\
II & $18(47 \%)$ & $0(0 \%)$ \\
III & $3(8 \%)$ & $0(0 \%)$ \\
IV & $15(40 \%)$ & \\
\hline
\end{tabular}

Van Slooten index and Weiss score were not available for all patients, dependent on the year of diagnosis. ENSAT, European Network for the Study of Adrenal Tumors; IQR, interquartile range.

(c) 2019 Society for Endocrinology Published by Bioscientifica Ltd. Printed in Great Britain 
E
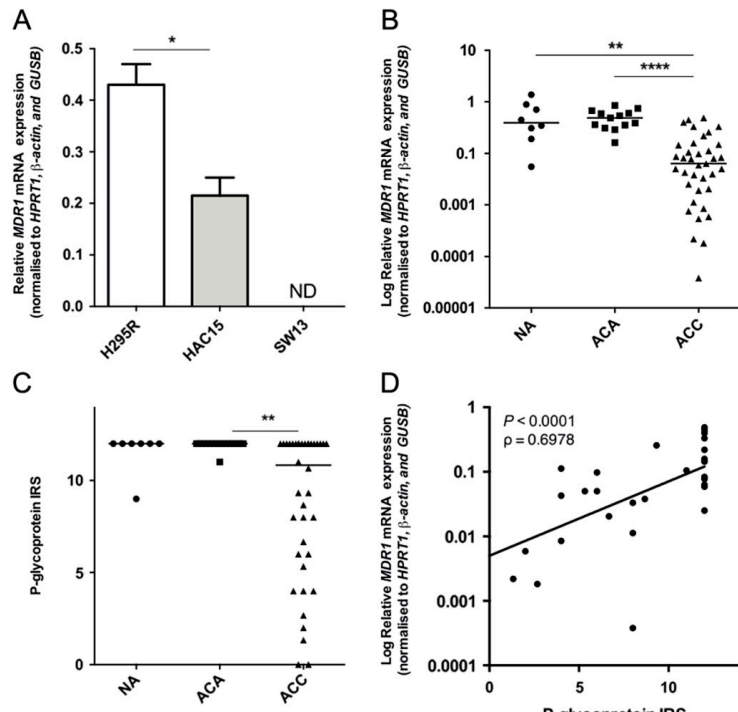

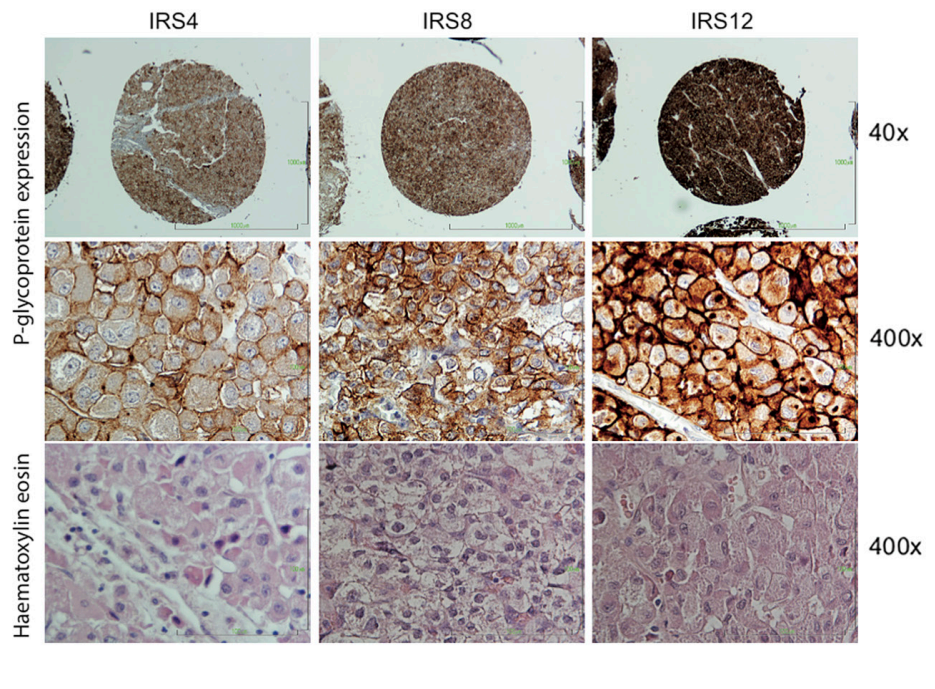

Figure 1

MDR1 mRNA expression in adrenal cell lines (A) and adrenal tissues (B) and P-glycoprotein expression in human adrenocortical tissues (C). Correlation between MDR1 mRNA expression and P-glycoprotein expression in ACCs (D). Representative example of P-gp immunohistochemical staining in adrenocortical carcinoma as determined by immunohistochemistry (E). Sections were blinded and independently evaluated by two investigators. Microscopic magnification 40×, 200x, and 400x. Lines represent medians. $\rho$ represents Spearman's rank correlation coefficient. $* P<0.05$, $* \star P<0.01$, $\star * \star * P<0.0001$. ACA, adrenocortical adenoma; ACC, adrenocortical carcinoma; IRS, immunoreactivity score; NA, normal adrenals; ND, not detectable.

9.8 (range 0-12; Fig. 1C). Staining was primarily located in the cell membrane (Fig. 1E). P-gp expression was significantly lower in ACCs compared to ACAs $(P<0.01$; Fig. 1C), which seems to be primarily driven by a subgroup of ACC patients with a P-gp expression below the median. MDR1 mRNA expression was positively correlated with P-gp expression not only in the whole group of patients $(P<0.0001, \rho=0.723)$ but also in the group of ACCs separately $(P<0.0001, \rho=0.6978$; Fig. 1D). No correlations were found between MDR1 mRNA or P-gp expression and the Van Slooten index or the Weiss score. Expression levels were also comparable between different ENSAT stages. MDR1 mRNA expression was negatively correlated with the maximum tumor diameter in ACCs $(P=0.002, \rho=-0.461)$. Furthermore, P-gp expression was significantly higher in cortisol-producing ACC than in other ACC $(P=0.048, n=38)$.

\section{Effects of cytotoxic drugs on human adrenocortical carcinoma cell lines}

H295R, HAC15 and SW13 demonstrated a dose-dependent inhibitory response to mitotane ( $\mathrm{EC}_{50}$ range: $2.63-12.3 \mu \mathrm{M}$ ), doxorubicin $\quad\left(\mathrm{EC}_{50}\right.$ range: $\left.0.0110-0.0608 \mu \mathrm{M}\right)$, etoposide $\left(\mathrm{EC}_{50}\right.$ range: $\left.0.175-0.708 \mu \mathrm{M}\right)$ and cisplatin (EC 50 range: $0.579-1.14 \mu \mathrm{M})$, but not to streptozotocin (Fig. 2 and Table 2).
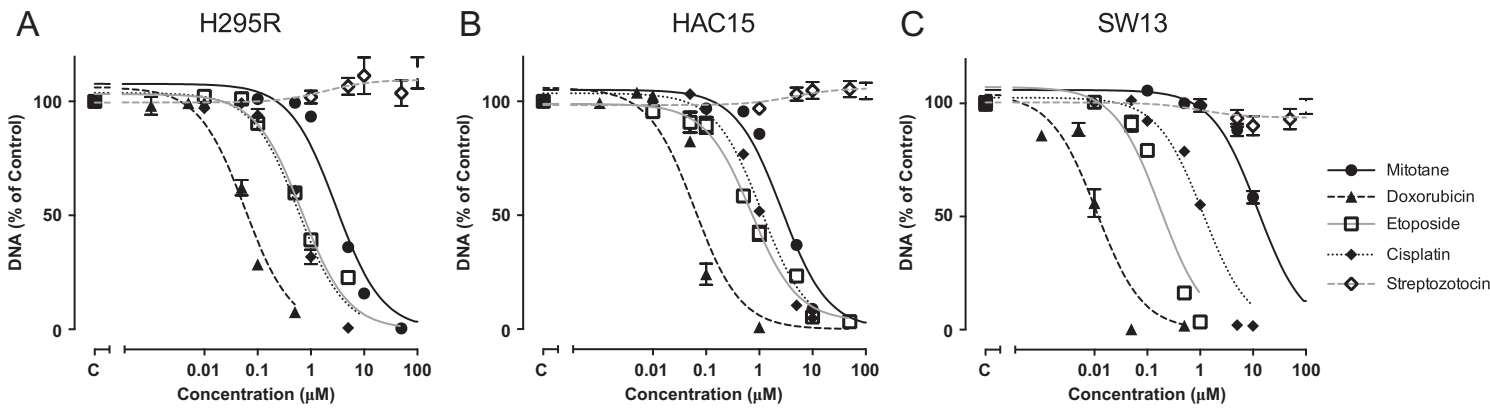

\section{Figure 2}

Dose-response curves of mitotane, doxorubicin, etoposide, cisplatin and streptozotocin on total DNA measurement, as a measure of cell amount, in H295R (left panel), HAC15 (middle panel) and SW13 (right panel) after 7 days of treatment. Values represent mean \pm S.E.M. and are shown as percentage of control. 
Table $2 \mathrm{EC}_{50}$ values of mitotane, doxorubicin, cisplatin and etoposide on cell growth in human adrenocortical cell lines with or without the P-gp inhibitors verapamil or tariquidar.

\begin{tabular}{|c|c|c|c|}
\hline & & MIT & DOX \\
\hline \multirow[t]{3}{*}{ H295R } & Monotherapy & $2.96(2.47-3.56)$ & $0.0575(0.0415-0.0795)$ \\
\hline & + Verapamil & $2.70(2.11-3.44)$ & $0.00765(0.00596-0.00982) * * * *$ \\
\hline & + Tariquidar & $2.45(1.64-3.66)^{*}$ & $0.00914(0.00582-0.0144)^{\star * \star *}$ \\
\hline \multirow[t]{3}{*}{ HAC15 } & Monotherapy & $2.63(3.03-4.13)$ & $0.0608(0.0464-0.0796)$ \\
\hline & + Verapamil & $3.45(2.56-4.65)^{*}$ & $0.0435(0.0293-0.0647)$ \\
\hline & + Tariquidar & $2.65(1.77-3.96)$ & $0.0152(0.0103-0.0225)^{\star \star * *}$ \\
\hline \multirow[t]{3}{*}{ SW13 } & Monotherapy & $12.3(9.09-16.7)$ & $0.0110(0.00694-0.0175)$ \\
\hline & + Verapamil & $9.57(5.85-15.6)$ & $0.0130(0.00873-0.0194)$ \\
\hline & + Tariquidar & $9.25(6.53-13.1)^{*}$ & $0.0109(0.00720-0.0165)$ \\
\hline
\end{tabular}

\begin{tabular}{|c|}
\hline ETO \\
\hline $0.674(0.565-0.803)$ \\
\hline $0.181(0.124-0.265)^{\star \star \star *}$ \\
\hline $0.0732(0.0596-0.0900) * * \star *$ \\
\hline $0.708(0.576-0.870)$ \\
\hline 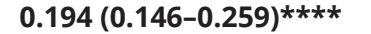 \\
\hline $0.116(0.0836-0.161) * * * *$ \\
\hline $0.175(0.112-0.275)$ \\
\hline $0.116(0.0768-0.174)^{* *}$ \\
\hline $0.169(0.0926-0.308)$ \\
\hline
\end{tabular}

\begin{tabular}{c}
\hline CIS \\
\hline $0.579(0.460-0.728)$ \\
$0.676(0.556-0.822)$ \\
$1.48(1.12-1.95)^{\star * \star *}$ \\
$1.10(0.907-1.322)$ \\
$\mathbf{0 . 8 5 5}(\mathbf{0 . 6 6 8 - 1 . 1 0 ) *}$ \\
$3.73(3.17-4.39)^{\star * * *}$ \\
$1.14(0.897-1.44)$ \\
$\mathbf{0 . 7 3 1}(\mathbf{0 . 5 6 4 - 0 . 9 4 9 ) * * * *}$ \\
$3.51(1.96-6.31)^{\star * * *}$ \\
\hline
\end{tabular}

$\mathrm{EC}_{50}$ values are presented in micromolar $(\mu \mathrm{M}, 95 \% \mathrm{Cl})$. Controls represent vehicle control for monotherapy of cytotoxic drugs, and treatment with verapamil $(10 \mu \mathrm{M})$ or tariquidar $(1 \mu \mathrm{M})$ for combination therapy. $P$ values compare $\mathrm{EC}_{50}$ value of combination therapy with P-gp inhibitors verapamil or tariquidar to monotherapy of either mitotane (MIT), doxorubicin (DOX), etoposide (ETO), or cisplatin (CIS). EC ${ }_{50}$ values depicted in bold are significantly lower compared to monotherapy. $* P<0.05, * * P<0.01, * * * P<0.001, * * * * P<0.0001$

\section{Effects of the P-gp inhibitors verapamil and tariquidar on the response of human adrenocortical carcinoma cell lines to cytotoxic drugs}

First, we examined the possible effects of verapamil and tariquidar alone on cell growth in H295R, HAC15 and SW13. To avoid cytotoxicity, a concentration of $10 \mu \mathrm{M}$ verapamil and $1 \mu \mathrm{M}$ tariquidar was chosen for combination experiments with cytotoxic drugs. Verapamil and tariquidar in these concentrations only minimally affected cell growth in HAC15 with respectively 11 and 9.7\% $(P<0.001)$, whereas no effects were observed in H295R and SW13 on cell growth. Subsequently, we analyzed whether both P-gp inhibitors could sensitize ACC cells reflected by a decrease in the $\mathrm{EC}_{50}$ value of the cytotoxic drugs currently used for treatment of ACC (Fig. 3 and Table 2).

When tariquidar was added to different doses of mitotane, sensitivity to mitotane only modestly increased in H295R and SW13, with 1.2- and 1.3-fold lower $\mathrm{EC}_{50}$ values, respectively (both $P<0.05$ vs mitotane monotherapy). Verapamil, however, decreased the response to mitotane in HAC15, but not in H295R and SW13 $(P<0.05$ vs mitotane monotherapy). Verapamil and tariquidar both increased the response of H295R cells to doxorubicin, as shown by a 7.5- and 6.3-fold decrease in $\mathrm{EC}_{50}$ value compared to doxorubicin monotherapy, respectively (both $P<0.0001$ vs doxorubicin monotherapy). In HAC15, sensitivity to doxorubicin only increased when tariquidar was used as shown by a 4 -fold decrease in $\mathrm{EC}_{50}(P<0.0001$ vs doxorubicin monotherapy). Sensitivity to doxorobucin did not change in SW13 cells with addition of P-gp inhibitors. Sensitivity to etoposide increased when the compound was combined with verapamil or tariquidar, as indicated by a 3.7- and 9.2-fold significant decrease in $\mathrm{EC}_{50}$ value in $\mathrm{H} 295 \mathrm{R}$ and a 3.6 and 6.1 times decrease in HAC15, respectively. In both H295R and HAC15 cells, tariquidar more strongly sensitized cells to etoposide compared to verapamil (both $P<0.01$ vs etoposide monotherapy). In SW13, effects of etoposide were only slightly potentiated by verapamil (2.0-fold decrease in $\left.\mathrm{EC}_{50} ; P<0.0001\right)$. In all three ACC cell lines, tariquidar counteracted the effect of cisplatin on cell growth (range increase $\mathrm{EC}_{50} 2.6-3.4$ fold; all $P<0.0001$ vs cisplatin monotherapy). In HAC15 and SW13, verapamil increased sensitivity to cisplatin $(P<0.05, P<0.0001$, respectively).

\section{Effects of cytotoxic drugs, with and without P-gp inhibitors, on colony formation in human ACC cell lines}

The effects of the compounds with and without P-gp inhibitors on colony formation appeared to primarily be cytotoxic, as stated by an effect on the fraction of colonies rather than an effect on colony size. Effects on the size of colonies are presented in Supplementary Fig. 1. In H295R, mitotane in combination with tariquidar resulted in a less strong effect on surviving fraction of colonies compared to mitotane alone ( $P<0.01$ vs mitotane monotherapy). In HAC15, verapamil counteracted whereas tariquidar potentiated the effect of mitotane (Fig. 4B; $P<0.0001$, $P<0.05$, respectively). Both verapamil and tariquidar strongly potentiated the effects of doxorubicin in H295R and HAC15 (all $P<0.0001$ vs doxorubicin monotherapy). P-gp inhibition did not alter cytotoxic effects of mitotane and doxorubicin in SW13 cells. (c) 2019 Society for Endocrinology Published by Bioscientifica Ltd. Printed in Great Britain 
H295R
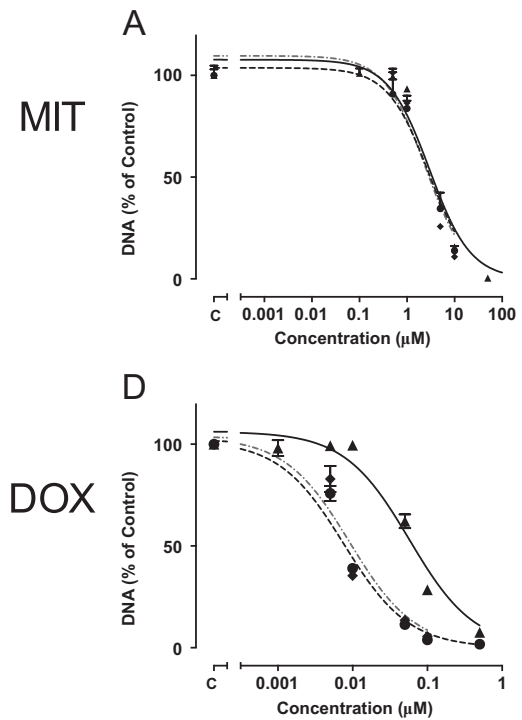

G
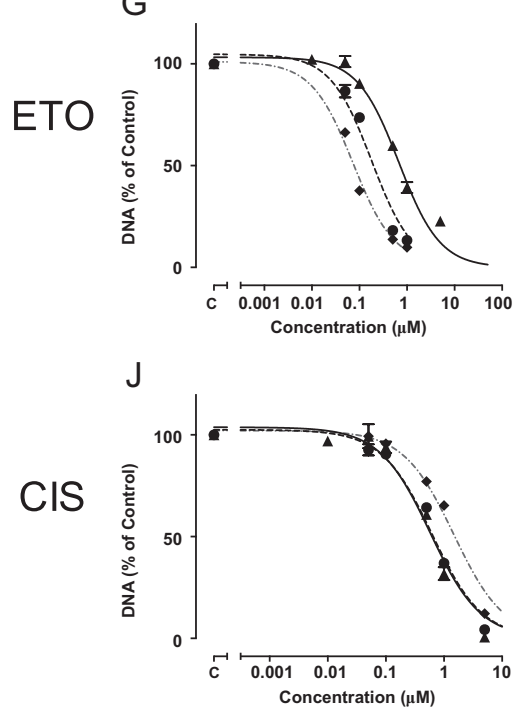

HAC15

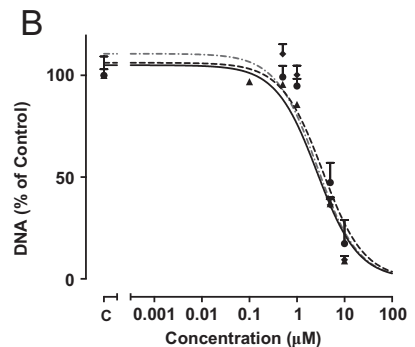

$E$

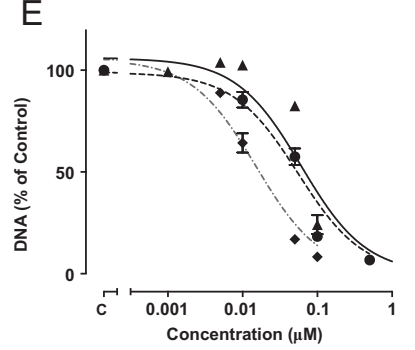

$\mathrm{H}$

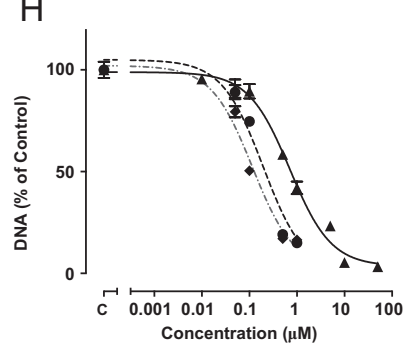

$\kappa$

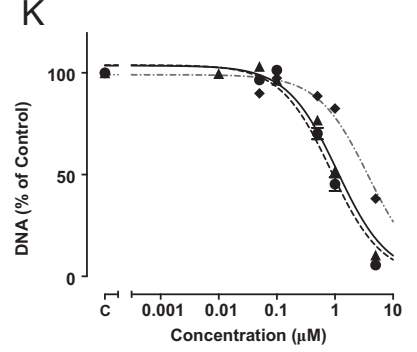

SW13

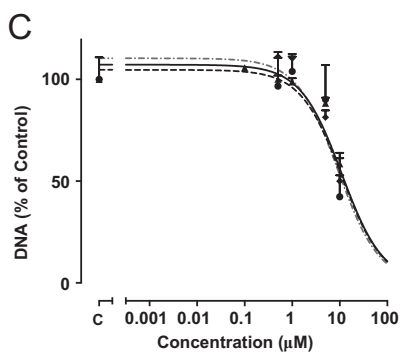

F

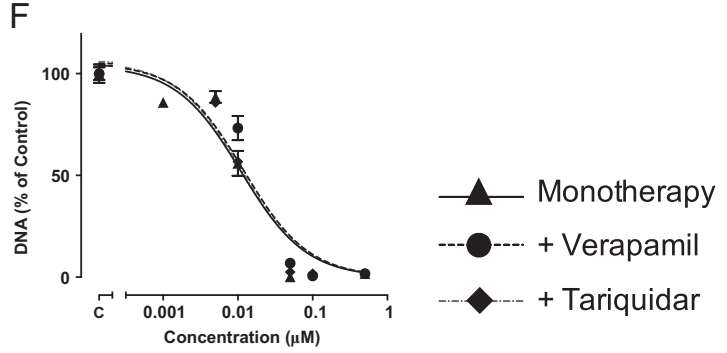

I

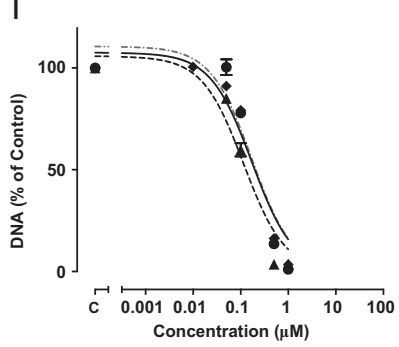

L

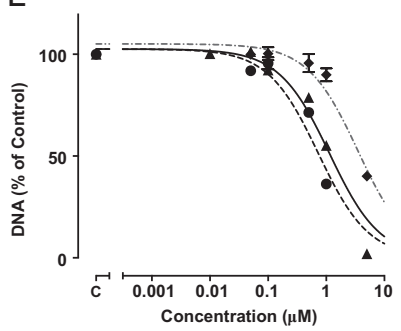

\section{Figure 3}

Effects of mitotane (MIT), doxorubicin (DOX), etoposide (ETO) and cisplatin (CIS), with or without the P-gp inhibitors verapamil (10 $\mu \mathrm{M})$ or tariquidar (1 $\mu \mathrm{M})$ on cell growth in three human ACC cell lines H295R (left panel), HAC15 (middle panel) and SW13 (right panel) after 7 days of treatment. Gray solid lines represent the effect of monotherapy. Dotted lines represent the combination of verapamil (black dotted lines) or tariquidar (gray dotted lines) with cytotoxic therapy. Data are presented as percentage of vehicle treated control. When combination of cytotoxic drugs with verapamil (+V) or tariquidar $(+\mathrm{T})$ were examined, the control was set as verapamil $(10 \mu \mathrm{M})$ or tariquidar $(1 \mu \mathrm{M})$ monotherapy, respectively. Values represent mean \pm S.E.M. and are shown as percentage of control.

In H295R, the effect of etoposide on surviving fraction of colonies was enhanced when combined with verapamil or tariquidar (Fig. 4G; both $P<0.05$ vs etoposide monotherapy), whereas this effect in HAC15 was only observed in combination with tariquidar $(P<0.01$ vs etoposide monotherapy). In SW13, verapamil potentiated the effect of etoposide (Fig. 4I; P<0.01). In H295R, the effect of cisplatin was slightly counteracted by tariquidar $(P<0.001$ vs cisplatin monotherapy), whereas no effects were seen on sensitivity to cisplatin in HAC15 and SW13.

\section{Discussion}

In this study, we show that P-gp is highly expressed in normal and neoplastic adrenal tissues, with lower levels in ACC compared to ACA and NA. Previously, it has been shown that verapamil might increase sensitivity to 
HAC15

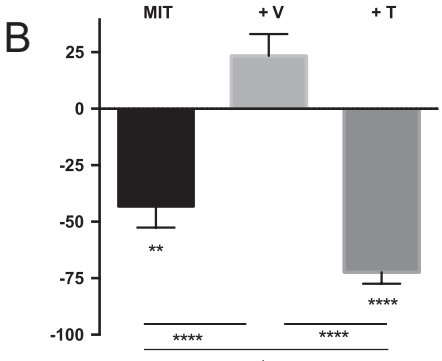

E

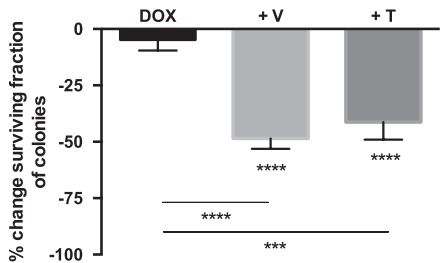

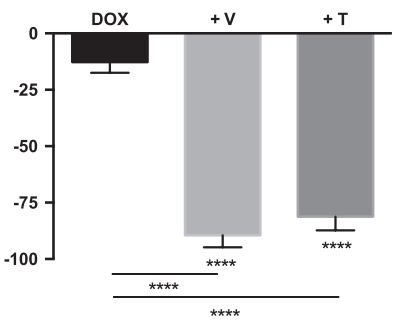

$\mathrm{H}$

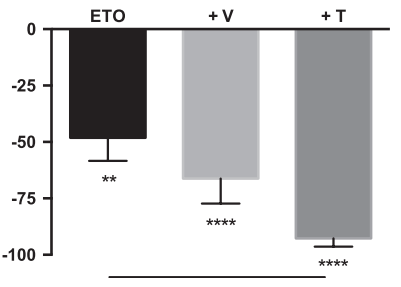

K

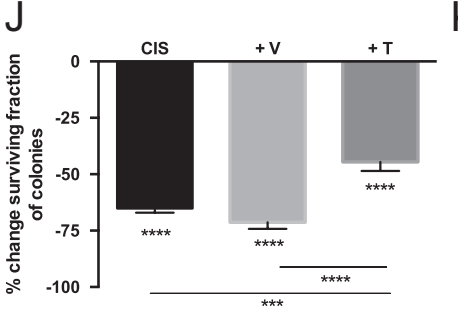

G

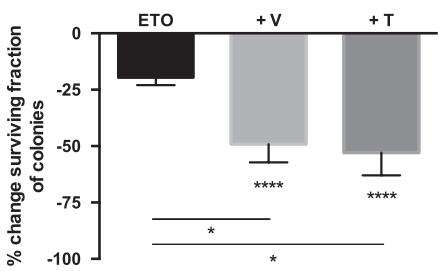

CIS

Figure 4

Effects of cytotoxic drugs with or without the P-gp inhibitors verapamil (V) or tariquidar (T) on the surviving fraction of colonies in H295R (left panel), HAC15 (middle panel) and SW13 (right panel). Data are presented as percentage change compared to vehicle treated control. When combination of cytotoxic drugs with verapamil $(+\mathrm{V})$ or tariquidar $(+\mathrm{T})$ were examined, the control was set as verapamil $(10 \mu \mathrm{M})$ or tariquidar $(1 \mu \mathrm{M})$ monotherapy, respectively. ${ }^{*} P<0.05, * \star P<0.01, * * \star P<0.001, * \star * \star P<0.0001$ vs vehicle treated control or as stated by the lines. CIS, cisplatin; DOX, doxorubicin; ETO, etoposide; MIT, mitotane. Values represent mean \pm S.E.M.

doxorubicin in ACC (Gagliano et al. 2014). This is the first study investigating the effects of verapamil and the clinically more promising P-gp inhibitor tariquidar on a panel of the most important clinically used chemotherapeutic drugs for ACC. We demonstrate that inhibition of P-gp in human ACC cells in vitro can increase sensitivity to specific cytotoxic drugs, used to treat ACC in vivo.

Chemotherapeutic drugs have demonstrated disappointing results in ACC patients so far. Targeting P-gp expression would potentially increase tumor cell exposure to cytotoxic agents and thereby improve the efficacy of chemotherapy. In this study, we confirm the previously reported high P-gp expression in the majority of ACC cases (Flynn et al. 1992, Haak et al. 1993, Backlin et al. 1994). MDR1 mRNA expression and P-gp expression are positively correlated in ACCs and lower in ACCs than in ACAs. The lower expression in ACCs compared to ACAs might potentially be the result of involvement of the MDR1 gene in the pathogenesis of ACC, as P-gp silencing is also an early event in colorectal carcinogenesis 
(Andersen et al. 2013). Dedifferentiation of ACCs could be another explanation of lower MDR1 mRNA and P-gp expression, although no correlation was found with histopathology. ACCs appeared to have a more variable P-gp expression compared to ACAs and NAs, and the hypothesis is that ACC patients with high P-gp expression might be more resistant to chemotherapeutic drugs, and these patients may particularly benefit from simultaneous treatment with P-gp inhibitors. Most importantly, the majority of patients seem to have P-gp expression comparable with NAs, whose expression is thought to be high relative to other normal tissues (Thiebaut et al. 1987, Cordon-Cardo et al. 1990, Sugawara 1990). Furthermore, these ACC cases have MDR1 mRNA expression comparable with the expression in the cell lines that have been used as a model.

Previously, the antitumoral effects of the M-EDP regimen were already demonstrated in NCI-H295R cells in vitro and in xenografts (Hantel et al. 2014). In the present study, we report the in vitro effects, in pharmacological concentrations, of currently used cytotoxic drugs in ACC separately. Surprisingly, streptozotocin did not inhibit the growth of ACC cells in vitro. The first rationale for streptozotocin in the treatment of ACC was based on increased concentration of streptozotocin in the mice adrenal cortex after i.v. injection (Tjalve et al. 1976). In the FIRM-act trial, however, streptozotocin in combination with mitotane appeared to be less effective compared to the M-EDP regimen (Fassnacht et al. 2012), which turns out to be concordant with our in vitro results. We demonstrate that the other drugs used to treat ACC (mitotane, cisplatin, etoposide and doxorubicin) effectively inhibited cell growth in ACC cell lines, all with $\mathrm{EC}_{50}$ values within the range of achievable plasma concentrations after administration in humans (Baudin et al. 2001, Urien \& Lokiec 2004, Barpe et al. 2010, Tazawa et al. 2016). An important consideration is that plasma concentrations do not necessarily represent intratumoral concentrations.

The findings on cell growth inhibition in ACC cell lines were confirmed by performing a CFA, which predominantly revealed comparable results. There is a clear difference between both assays; the CFA provides information on the long-term effects (2 weeks without treatment) of a short-term (3 days) treatment with cytotoxic drugs on colony growth, whereas the cell growth assay studies the direct effect of cytotoxic drugs after 7 days of treatment. This difference could explain inequalities in effect of compounds. In H295R and HAC15, especially an increased response to doxorubicin and etoposide was found under P-gp inhibition both on cell growth and on the surviving fraction of colonies. Increased sensitivity can be explained by the fact that doxorubicin and etoposide are substrates of P-gp (Sharom 2008). In a study investigating the effects of mitotane on drug elimination pathways, it was suggested that mitotane retained its antineoplastic efficacy even in tumors overexpressing drug transporters, due to lack of substrate characteristics (Theile et al. 2015). Another explanation of lack of increased sensitivity to mitotane could be potential P-gp inhibition, although the role of mitotane in P-gp inhibition is debatable (Bates et al. 1991, Gagliano et al. 2014, Theile et al. 2015). In line with this finding, only subtle differences in mitotane sensitivity were observed under P-gp inhibition on cell growth in ACC cells in our study. P-gp inhibition also only minimally affected the cytotoxic effects of mitotane on colony formation in H295R and SW13. In HAC15, however, verapamil counteracted the effect of mitotane on colony formation, corresponding with the effect in monolayer culture on cell growth. The minimal or even absence of enhanced cisplatin effects after co-treatment with verapamil in H295R, HAC15 and SW13 could be explained by the fact that cisplatin is not a substrate of P-gp, but of several MDR1-related proteins (MRPs) (Jedlitschky et al. 2006). Decreased sensitivity to cisplatin was particularly observed with respect to cell growth when cisplatin was combined with tariquidar and was confirmed in H295R in the CFA. This attenuated sensitivity could potentially be explained by a compensatory increase in drug efflux by other transporters. Compensatory upregulation of other transporters has been demonstrated in mutant animals with deficiency of a specific drug efflux transporter (Johnson et al. 2006). This in turn would indicate that it could be required to inhibit multiple drug transporters to reach optimal efficacy, which would also be reasonable in case there is expression of other $\mathrm{ABC}$ transporters in ACC as well. This could be subject to further investigation in ACC. In SW13, effects of P-gp inhibitors in general were much less pronounced, which is concordant with the undetectable MDR1 mRNA expression in SW13 cells, in contrast to H295R and HAC15.

In preclinical studies, the question always arises whether the obtained findings can be translated to clinical practice. The present study uses ACC cell lines. Considering the limited availability of ACC cell line models, a subclone of H295R was also used (HAC15), aiming to obtain a better representation of the heterogeneity of ACC. Further research could focus on primary cultures. Finally, tariquidar in combination with mitotane, doxorubicin 
and etoposide could be tested in ACC patients with disease progression under the conventional M-EDP regimen. Tariquidar is well tolerated and a peak serum concentration of $2.3 \mu \mathrm{M}$ can be reached (Wagner et al. 2009, Bauer et al. 2013). In the present study, a lower concentration $(1 \mu \mathrm{M})$ was used and appeared to significantly increase sensitivity to doxorubicin and etoposide. Tariquidar in vivo already demonstrated to induce inhibition of P-gp in patients with ACC as determined by increased accumulation of 99mTc-sestamibi in ACC lesions and blockade of rhodamine efflux in CD56+ mononuclear cells (Menefee et al. 2008). Where verapamil is often used as a positive control for P-gp inhibition in preclinical studies, tariquidar and other third-generation P-gp inhibitors are currently evaluated in several clinical trials in other types of cancer. The fact that this preclinical study combines currently clinically used chemotherapeutic drugs with a P-gp inhibitor that is already investigated in patients with ACC could lead to a faster introduction in clinical trials aiming to improve sensitivity to chemotherapy in ACC. A recent review summarized the efficacy of clinical trials using third-generation P-gp inhibitors until now, revealing however disappointing results in general (Chung et al. 2016). Several challenges have been encountered such as the limited fraction of tumors expressing the MDR1 gene. P-gp is for instance expressed in less than $50 \%$ of breast cancers (Trock et al. 1997). No preselection based on P-gp expression was made in previous clinical trials. In ACCs, however, we show that P-gp is expressed in 95\% of cases, of which $78 \%$ of all cases with an IRS of at least six. This observation provides a rationale for targeting this transporter in selected patients, which is associated with the limitation that P-gp inhibition might not be effective in a subgroup of ACC patients. An important consideration, however, is that P-gp expression can be upregulated following chemotherapy (Zhou et al. 1995, Chevillard et al. 1996), so baseline P-gp expression levels may not be predictive for clinical outcome of combined treatment with chemotherapy and P-gp inhibition. The large variability of P-gp expression observed in the present ACC panel could not be caused by upregulation, since no patients were pretreated with chemotherapy, and only two patients received mitotane before surgery. Thereby, we have to acknowledge that P-gp is only one of the multitudes of mechanisms that can lead to drug resistance, and P-gp is part of a family of ABC transporters (Sharom 2008).

In conclusion, we show that cytotoxic drugs, except streptozotocin, used for treatment of ACC inhibit cell growth in ACC cell lines. P-glycoprotein is expressed in

C) 2019 Society for Endocrinology Published by Bioscientifica Ltd. Printed in Great Britain
ACC, expression level is in the majority of cases comparable with the high expression in NAs, and inhibition of P-gp increases sensitivity to particularly doxorubicin and etoposide. This study thereby marks the relevance of carefully selecting compounds as well as patients when designing clinical trials with P-gp inhibitors in patients with ACC. These findings suggest that the MDR1 gene plays a role in sensitivity of ACC cells to these cytotoxic drugs and could be a potential target for improvement of efficacy of cytotoxic drugs in ACCs.

\section{Supplementary data}

This is linked to the online version of the paper at https://doi.org/10.1530/ ERC-18-0500.

\section{Declaration of interest}

The authors declare that there is no conflict of interest that could be perceived as prejudicing the impartiality of the research reported.

\section{Funding}

This research did not receive any specific grant from any funding agency in the public, commercial or not-for-profit sector.

\section{Acknowledgements}

The authors would like to thank Dr E Korpershoek for developing the TMA. The authors would like to thank Mrs M Baidjnath Misier for the effort in setting up the project and data analysis and Mrs W Geilvoet for excellent patient care.

\section{References}

Abraham J, Bakke S, Rutt A, Meadows B, Merino M, Alexander R, Schrump D, Bartlett D, Choyke P, Robey R, et al. 2002 A phase II trial of combination chemotherapy and surgical resection for the treatment of metastatic adrenocortical carcinoma: continuous infusion doxorubicin, vincristine, and etoposide with daily mitotane as a P-glycoprotein antagonist. Cancer 94 2333-2343. (https://doi. org/10.1002/cncr.10487)

Allolio B \& Fassnacht M 2006 Clinical review: adrenocortical carcinoma: clinical update. Journal of Clinical Endocrinology and Metabolism 91 2027-2037. (https://doi.org/10.1210/jc.2005-2639)

Andersen V, Vogel U, Godiksen S, Frenzel FB, Saebo M, Hamfjord J, Kure E \& Vogel LK 2013 Low ABCB1 gene expression is an early event in colorectal carcinogenesis. PLoS One 8 e72119. (https://doi. org/10.1371/journal.pone.0072119)

Backlin C, Fridborg H, Juhlin C, Nygren P, Akerstrom G, Rastad J \& Larsson R 1994 Variable p-glycoprotein immunoreactivity unrelated to cytotoxic drug-resistance in-vitro of human adrenocortical carcinoma. International Journal of Oncology 5 565-571. (https://doi. org/10.3892/ijo.5.3.565)

Barpe DR, Rosa DD \& Froehlich PE 2010 Pharmacokinetic evaluation of doxorubicin plasma levels in normal and overweight patients with breast cancer and simulation of dose adjustment by different indexes 
of body mass. European Journal of Pharmaceutical Sciences 41 458-463. (https://doi.org/10.1016/j.ejps.2010.07.015)

Bates SE, Shieh CY, Mickley LA, Dichek HL, Gazdar A, Loriaux DL \& Fojo AT 1991 Mitotane enhances cytotoxicity of chemotherapy in cell lines expressing a multidrug resistance gene (mdr-1/P-glycoprotein) which is also expressed by adrenocortical carcinomas. Journal of Clinical Endocrinology and Metabolism $\mathbf{7 3}$ 18-29. (https://doi.org/10.1210/jcem-73-1-18)

Baudin E, Pellegriti G, Bonnay M, Penfornis A, Laplanche A, Vassal G \& Schlumberger M 2001 Impact of monitoring plasma 1,1-dichlorodiphenildichloroethane (o,p'DDD) levels on the treatment of patients with adrenocortical carcinoma. Cancer 92 1385-1392. (https://doi.org/10.1002/10970142(20010915)92:6<1385::AID-CNCR1461>3.0.CO;2-2)

Bauer M, Zeitlinger M, Todorut D, Bohmdorfer M, Muller M, Langer O \& Jager W 2013 Pharmacokinetics of single ascending doses of the P-glycoprotein inhibitor tariquidar in healthy subjects. Pharmacology 91 12-19. (https://doi.org/10.1159/000343243)

Bellantone R, Ferrante A, Boscherini M, Lombardi CP, Crucitti P, Crucitti F, Favia G, Borrelli D, Boffi L, Capussotti L, et al. 1997 Role of reoperation in recurrence of adrenal cortical carcinoma: results from 188 cases collected in the Italian National Registry for adrenal cortical carcinoma. Surgery 122 1212-1218. (https://doi.org/10.1016/ S0039-6060(97)90229-4)

Benson AB, 3rd, Trump DL, Koeller JM, Egorin MI, Olman EA, Witte RS, Davis TE \& Tormey DC 1985 Phase I study of vinblastine and verapamil given by concurrent IV infusion. Cancer Treatment Reports 69 795-799.

Chevillard S, Pouillart P, Beldjord C, Asselain B, Beuzeboc P, Magdelenat H \& Vielh P 1996 Sequential assessment of multidrug resistance phenotype and measurement of S-phase fraction as predictive markers of breast cancer response to neoadjuvant chemotherapy. Cancer 77 292-300. (https://doi.org/10.1002/ (SICI)1097-0142(19960115)77:2<292::AID-CNCR11>3.0.CO;2-X)

Chung FS, Santiago JS, Jesus MF, Trinidad CV \& See MF 2016 Disrupting P-glycoprotein function in clinical settings: what can we learn from the fundamental aspects of this transporter? American Journal of Cancer Research 6 1583-1598.

Cordon-Cardo C, O’Brien JP, Boccia J, Casals D, Bertino JR \& Melamed MR 1990 Expression of the multidrug resistance gene product (P-glycoprotein) in human normal and tumor tissues. Journal of Histochemistry and Cytochemistry 38 1277-1287. (https:// doi.org/10.1177/38.9.1974900)

Creemers SG, Hofland LJ, Korpershoek E, Franssen GJ, van Kemenade FJ, de Herder WW \& Feelders RA 2016a Future directions in the diagnosis and medical treatment of adrenocortical carcinoma. Endocrine-Related Cancer 23 R43-R69. (https://doi.org/10.1530/ERC-15-0452)

Creemers SG, van Koetsveld PM, van Kemenade FJ, Papathomas TG, Franssen GJ, Dogan F, Eekhoff EM, van der Valk P, de Herder WW, Janssen JA, et al. $2016 b$ Methylation of IGF2 regulatory regions to diagnose adrenocortical carcinomas. Endocrine-Related Cancer 23 727-737. (https://doi.org/10.1530/ERC-16-0266)

Fassnacht M, Johanssen S, Quinkler M, Bucsky P, Willenberg HS, Beuschlein F, Terzolo M, Mueller HH, Hahner S, Allolio B, et al. 2009 Limited prognostic value of the 2004 International Union Against Cancer staging classification for adrenocortical carcinoma: proposal for a revised TNM Classification. Cancer 115 243-250. (https://doi. org/10.1002/cncr.24030)

Fassnacht M, Terzolo M, Allolio B, Baudin E, Haak H, Berruti A, Welin S, Schade-Brittinger C, Lacroix A, Jarzab B, et al. 2012 Combination chemotherapy in advanced adrenocortical carcinoma. New England Journal of Medicine 366 2189-2197. (https://doi.org/10.1056/ NEJMoa1200966)

Flynn SD, Murren JR, Kirby WM, Honig J, Kan L \& Kinder BK 1992 P-glycoprotein expression and multidrug resistance in adrenocortical carcinoma. Surgery 112 981-986.
Franken NA, Rodermond HM, Stap J, Haveman J \& van Bree C 2006 Clonogenic assay of cells in vitro. Nature Protocols 1 2315-2319. (https://doi.org/10.1038/nprot.2006.339)

Gagliano T, Gentilin E, Benfini K, Di Pasquale C, Tassinari M, Falletta S, Feo C, Tagliati F, Uberti ED \& Zatelli MC 2014 Mitotane enhances doxorubicin cytotoxic activity by inhibiting P-gp in human adrenocortical carcinoma cells. Endocrine 47 943-951. (https://doi. org/10.1007/s12020-014-0374-z)

Goldstein LJ, Galski H, Fojo A, Willingham M, Lai SL, Gazdar A, Pirker R, Green A, Crist W \& Brodeur GM 1989 Expression of a multidrug resistance gene in human cancers. Journal of the National Cancer Institute 81 116-124. (https://doi.org/10.1093/jnci/81.2.116)

Grubbs EG, Callender GG, Xing Y, Perrier ND, Evans DB, Phan AT \& Lee JE 2010 Recurrence of adrenal cortical carcinoma following resection: surgery alone can achieve results equal to surgery plus mitotane. Annals of Surgical Oncology 17 263-270. (https://doi. org/10.1245/s10434-009-0716-X)

Haak HR, van Seters AP, Moolenaar AJ \& Fleuren GJ 1993 Expression of P-glycoprotein in relation to clinical manifestation, treatment and prognosis of adrenocortical cancer. European Journal of Cancer 29A 1036-1038. (https://doi.org/10.1016/S0959-8049(05)80219-9)

Hahner S \& Fassnacht M 2005 Mitotane for adrenocortical carcinoma treatment. Current Opinion in Investigational Drugs 6 386-394.

Hantel C, Jung S, Mussack T, Reincke M \& Beuschlein F 2014 Liposomal polychemotherapy improves adrenocortical carcinoma treatment in a preclinical rodent model. Endocrine-Related Cancer 21 383-394. (https://doi.org/10.1530/ERC-13-0439)

Hofland LJ, van Koetsveld PM \& Lamberts SW 1990 Percoll density gradient centrifugation of rat pituitary tumor cells: a study of functional heterogeneity within and between tumors with respect to growth rates, prolactin production and responsiveness to the somatostatin analog SMS 201-995. European Journal of Cancer 26 37-44. (https://doi.org/10.1016/0277-5379(90)90254-Q)

Jedlitschky G, Hoffmann U \& Kroemer HK 2006 Structure and function of the MRP2 (ABCC2) protein and its role in drug disposition. Expert Opinion on Drug Metabolism and Toxicology 2 351-366. (https://doi. org/10.1517/17425255.2.3.351)

Johnson BM, Zhang P, Schuetz JD \& Brouwer KL 2006 Characterization of transport protein expression in multidrug resistance-associated protein (Mrp) 2-deficient rats. Drug Metabolism and Disposition 34 556-562. (https://doi.org/10.1124/dmd.105.005793)

Kannan P, Telu S, Shukla S, Ambudkar SV, Pike VW, Halldin C, Gottesman MM, Innis RB \& Hall MD 2011 The 'specific' P-glycoprotein inhibitor tariquidar is also a substrate and an inhibitor for breast cancer resistance protein (BCRP/ABCG2). ACS Chemical Neuroscience 2 82-89. (https://doi.org/10.1021/ cn100078a)

Lau SK \& Weiss LM 2009 The Weiss system for evaluating adrenocortical neoplasms: 25 years later. Human Pathology 40 757-768. (https://doi. $\operatorname{org} / 10.1016 /$ j.humpath.2009.03.010)

Libe R, Borget I, Ronchi CL, Zaggia B, Kroiss M, Kerkhofs T, Bertherat J, Volante M, Quinkler M, Chabre O, et al. 2015 Prognostic factors in stage III-IV adrenocortical carcinomas (ACC): an European Network for the Study of Adrenal Tumor (ENSAT) study. Annals of Oncology 26 2119-2125. (https://doi.org/10.1093/annonc/mdv329)

Margonis GA, Kim Y, Tran TB, Postlewait LM, Maithel SK, Wang TS, Glenn JA, Hatzaras I, Shenoy R, Phay JE, et al. 2016 Outcomes after resection of cortisol-secreting adrenocortical carcinoma. American Journal of Surgery 211 1106-1113. (https://doi.org/10.1016/j. amjsurg.2015.09.020)

Martin C, Berridge G, Mistry P, Higgins C, Charlton P \& Callaghan R 1999 The molecular interaction of the high affinity reversal agent XR9576 with P-glycoprotein. British Journal of Pharmacology 128 403-411. (https://doi.org/10.1038/sj.bjp.0702807)

Menefee ME, Huang H, Edgerly M, Kotz H, Merino M, Balis FM, Chen CC, Robey R \& Bates SE \& Fojo AT 2008 Effects of the 
P-glycoprotein (Pgp) antagonist tariquidar (XR-9576; TQD) on Pgp function as well as the toxicity and efficacy of combined chemotherapy in patients with metastatic adrenocortical cancer (mACC). Journal of Clinical Oncology 26 (15 Suppl) abstract 2543. (https://doi.org/10.1200/jco.2008.26.15_suppl.2543)

Palmeira A, Sousa E, Vasconcelos MH \& Pinto MM 2012 Three decades of P-gp inhibitors: skimming through several generations and scaffolds. Current Medicinal Chemistry 19 1946-2025. (https://doi. org/10.2174/092986712800167392)

Papathomas TG, Oudijk L, Zwarthoff EC, Post E, Duijkers FA, van Noesel MM, Hofland LJ, Pollard PJ, Maher ER, Restuccia DF, et al. 2014 Telomerase reverse transcriptase promoter mutations in tumors originating from the adrenal gland and extra-adrenal paraganglia. Endocrine-Related Cancer 21 653-661. (https://doi.org/10.1530/ERC13-0429)

Raderer M \& Scheithauer W 1993 Clinical trials of agents that reverse multidrug resistance. A literature review. Cancer 72 3553-3563. (https://doi.org/10.1002/1097-0142(19931215)72:12<3553::AIDCNCR2820721203>3.0.CO;2-B)

Remmele W \& Stegner HE 1987 A proposal for the standardization of the immunoreactive score (Irs) for the immunohistochemical demonstration of estrogen-receptors (er-Ica) in breast-cancer. Pathologia Europaea 8 138-140.

Sharom FJ 2008 ABC multidrug transporters: structure, function and role in chemoresistance. Pharmacogenomics 9 105-127. (https://doi. org/10.2217/14622416.9.1.105)

Sugawara I 1990 Expression and functions of P-glycoprotein (mdr1 gene product) in normal and malignant tissues. Acta Pathologica Japonica 40 545-553.

Tazawa Y, Shigematsu A, Kasashi K, Sugita J, Endo T, Kondo T, Teshima T, Iseki K, Sugawara M \& Takekuma Y 2016 Pharmacokinetics and dose adjustment of etoposide administered in a medium-dose etoposide, cyclophosphamide and total body irradiation regimen before allogeneic hematopoietic stem cell transplantation. Journal of Pharmaceutical Health Care and Sciences 2 18. (https://doi.org/10.1186/s40780-016-0052-9)

Theile D, Haefeli WE \& Weiss J 2015 Effects of adrenolytic mitotane on drug elimination pathways assessed in vitro. Endocrine 49 842-853. (https://doi.org/10.1007/s12020-014-0517-2)

Thiebaut F, Tsuruo T, Hamada H, Gottesman MM, Pastan I \& Willingham MC 1987 Cellular localization of the multidrugresistance gene product P-glycoprotein in normal human tissues. PNAS 84 7735-7738. (https://doi.org/10.1073/pnas.84.21.7735)
Tjalve H, Wilander E \& Johansson EB 1976 Distribution of labelled streptozotocin in mice: uptake and retention in pancreatic islets. Journal of Endocrinology 69 455-456. (https://doi.org/10.1677/ joe.0.0690455)

Trock BJ, Leonessa F \& Clarke R 1997 Multidrug resistance in breast cancer: a meta-analysis of MDR1/gp170 expression and its possible functional significance. Journal of the National Cancer Institute $\mathbf{8 9}$ 917-931. (https://doi.org/10.1093/jnci/89.13.917)

Tsuruo T, Iida H, Tsukagoshi S \& Sakurai Y 1981 Overcoming of vincristine resistance in P388 leukemia in vivo and in vitro through enhanced cytotoxicity of vincristine and vinblastine by verapamil. Cancer Research 41 1967-1972.

Urien S \& Lokiec F 2004 Population pharmacokinetics of total and unbound plasma cisplatin in adult patients. British Journal of Clinical Pharmacology 57 756-763. (https://doi.org/10.1111/ j.1365-2125.2004.02082.x)

van Koetsveld PM, Vitale G, de Herder WW, Feelders RA, van der Wansem K, Waaijers M, van Eijck CH, Speel EJ, Croze E, van der Lely AJ, et al. 2006 Potent inhibitory effects of type I interferons on human adrenocortical carcinoma cell growth. Journal of Clinical Endocrinology and Metabolism 91 4537-4543. (https://doi. org/10.1210/jc.2006-0620)

van Slooten H, Schaberg A, Smeenk D \& Moolenaar AJ 1985 Morphologic characteristics of benign and malignant adrenocortical tumors. Cancer 55 766-773. (https://doi.org/10.1002/10970142(19850215)55:4<766::AID-CNCR2820550414>3.0.CO;2-7)

Vandesompele J, De Preter K, Pattyn F, Poppe B, Van Roy N, De Paepe A \& Speleman F 2002 Accurate normalization of real-time quantitative RT-PCR data by geometric averaging of multiple internal control genes. Genome Biology 3 RESEARCH0034. (https://doi.org/10.1186/ gb-2002-3-7-research0034)

Wagner CC, Bauer M, Karch R, Feurstein T, Kopp S, Chiba P, Kletter K, Loscher W, Muller M, Zeitlinger M, et al. 2009 A Pilot Study to Assess the Efficacy of Tariquidar to Inhibit P-glycoprotein at the human blood-brain barrier with (R)-C-11-verapamil and PET. Journal of Nuclear Medicine 50 1954-1961. (https://doi.org/10.2967/ jnumed.109.063289)

Wang T \& Rainey WE 2012 Human adrenocortical carcinoma cell lines. Molecular and Cellular Endocrinology 351 58-65. (https://doi. org/10.1016/j.mce.2011.08.041)

Zhou DC, Zittoun R \& Marie JP 1995 Expression of multidrug resistanceassociated protein (MRP) and multidrug resistance (MDR1) genes in acute myeloid leukemia. Leukemia 9 1661-1666.

Received in final form 27 December 2018

Accepted 3 January 2019

Accepted Preprint published online 16 January 2019 (c) 2019 Society for Endocrinology Published by Bioscientifica Ltd. Printed in Great Britain 